\title{
Ventral Mesogastrium
}

National Cancer Institute

\section{Source}

National Cancer Institute. Ventral Mesogastrium. NCI Thesaurus. Code C34327.

The portion of the embryonic mesentery that is attached to the ventral abdominal wall, extending from the caudal foregut to the upper part of the duodenum. The liver develops within it, and it will give rise to the lesser omentum and falciform ligament. 